\title{
Literature Review : Sistem Skoring TB Anak Untuk Penegakan Diagnosis Dalam Pengendalian TB Anak
}

\author{
Literature Review: Pediatric TB Scoring System For The Establishment Of Diagnosis In \\ The Control Of TB In Children
}

\author{
Deni Lusiana \\ STIKES Panti Rapih Yogyakarta \\ Korespondensi Penulis: \\ Deni Lusiana \\ Email: bernadetha.deni@gmail.com
}

\begin{abstract}
Abstrak
Latar belakang: Sistem skoring TB anak merupakan pedoman untuk mendiagnosis anak terkena TB sehingga mempermudah petugas kesehatan untuk melakukan diagnosis TB pada anak. Dengan diagnosis TB anak yang tepat dapat memberikan pengobatan dan perawatan pada anak yang menderita TB dengan tepat pula, sehingga dapat menurunkan angka morbiditas dan mortalitas pada anak. Hal tersebut menjadi tolak ukur capaian keberhasilan program pengendalian TB anak di Indonesia. Tujuan penulisan ini adalah untuk mengetahui manfaat dan fungsi skoring TB anak dalam penegakan dignosis TB anak oleh petugas kesehatan supaya pengobatan TB menjadi cepat dan tepat. Metode: Artikel ini dibuat berdasarkan riview artikel yang berkaitan dengan sistem skoring TB anak dengan sumber lima tahun terakhir yaitu 2013-2019. Hasil: Dari artikel yang dianalisa menyatakan bahwa sistem skoring digunakan disemua tatanan pelayanan kesehatan tetapi juga bisa digunakan dipelayanan kesehatan dengan sarana yang terbatas untuk pemeriksaan diagnostik TB. Kesimpulan: Berdasarkan telusur literatur di Indonesia dan luar Negeri terdapat perbedaan dan persamaan item penilaian pada skoring TB anak. Walaupun pada akhirnya skoring TB anak tersebut membantu dalam penengakkan diagnosis TB paru pada anak. Skoring sudah dibakukan secara umum dan dapat digunakan oleh petugas kesehatan di semua tatanan pelayanan kesehatan sekalipun pelayanan yang masih memiliki sarana pemeriksaan dignostik yang terbatas.
\end{abstract}

Kata kunci: Anak, TB, Sistem Skoring

\begin{abstract}
Background: Pediatric TB scoring system is a tool for diagnosing children with TB, making it easier for health workers to diagnose TB in children. A proper diagnosis of TB in children will lead to proper treatment and care so as to reduce morbidity and mortality. This is a benchmark for the success of the pediatric TB control program in Indonesia. The aim of this paper is to determine the benefits and function of the pediatric $T B$ scoring in the establishment of the diagnosis of TB in children by health workers so that TB treatment is quick and appropriate. Methods: This article is composed based on the review of articles related to the pediatric TB scoring system sourced from the past five years, namely 2013-2019. Results: In the articles analyzed, it is stated that the scoring system is used in all categories of healthcare facilities, but can also be used in healthcare facilities with limited facilities for TB diagnostic tests. Conclusion: Based on the review of Indonesian and foreign literature, it is found that there are differences and similarities of scoring items in the pediatric TB scoring systems, although in the end they help in the establishment of diagnosis of pulmonary TB in children. The scoring system is already generally standardized and can be used by health workers in all categories of healthcare facilities, even in those with limited facilities for diagnostic tests.
\end{abstract}

Keywords: Pediatric TB, Scoring System 


\section{Pendahuluan}

Tuberkulosis merupakan penyakit menular yang disebabkan oleh bakteri mycobaterium tuberkulosa dan menjadi salah satu masalah kesehatan dunia termasuk di negara berkembang seperti Indonesia. Penyakit tuberkulosis bisa terjadi pada semua umur baik orang dewasa maupun pada anak-anak dan menjadi penyebab tingginya angka morbiditas dan mortalitas. Tuberkulosis pada anak dapat terjadi pada usia 0-14 tahun. Anak merupakan kelompok resiko tinggi terkena TB karena kekebalan tubuh yang belum optimal. ${ }^{(1)}$

Menurut WHO,(2019) diperkirakan sekitar 1 juta anak didunia terkena penyakit TB anak dan 233.000 anak meninggal dunia karena TB di tahun 2017. (2) Negara Afrika dan Asia Tenggara memiliki kasus TB tertingi. ${ }^{(3)}$ Indonesia merupakan salah satu negara Asia Tenggara dengan kejadian tuberkulosis anak tahun 2010 sampai 2018 berkisar pada $9.4 \%$ sampai $11 \%$. $^{(4)}$ Anak yang terinfeksi TB tidak selalu mengalami sakit TB dan sekitar $10-15 \%$ yang terinfeksi TB akan menjadi sakit TB. ${ }^{(5)}$

WHO menargetkan bahwa angka kejadian pada TB pada anak mencapai nol. Pencapaian ini memerlukan advokasi yang berkelanjutan, komitmen, mobilasi sumber daya dan upaya bersama yang ikut terlibat dalam penyedian perawatan kesehatan anak dan dalam kontrol TB. ${ }^{(2)}$ Pemberian terapi pencegahan pada anak terinfeksi TB akan mengurangi anak menderita sakit TB. ${ }^{(5)}$ Penyakit TB bila tidak diobati atau pengobatan yang tidak tuntas dapat menimbulkan komplikasi berbahaya bagi tubuh hingga kematian serta beresiko menularkan ke orang lain. ${ }^{(6)}$ Pengobatan dan pengendalian TB pada anak memberikan tantangan sendiri bagi pelayanan kesehatan. Toksisitas obat, ketepatan diagnosis awal dan kepatuhan pengobatan merupakan hal yang mengkhawatirkan dalam pengobatan anak dengan TB. Ketidakpatuhan obat juga sebagai salah satu faktor terjadinya multidrug-resistant TB yang nantinya akan memberikan kerumitan tersendiri dalam pengobatan dan beresiko besar dalam kegagalan pengobatan berkesinambungan serta berdampak pada kematian. ${ }^{(7)}$

Tidak tercapainya pengendalian TB, diduga karena berbagai hal seperti diagnosis yang tidak tepat, pengobatan yang tidak adekuat serta penanggulangan yang tidak dilaksanakan dengan tepat. Sulitnya menegakkan diagnosis TB pada anak mengakibatkan data TB anak terbatas. ${ }^{(8)}$ Selain itu dengan diagnosis yang tidak tepat menjadi salah satu penyebab pengobatan yang tidak tepat pula. Berdasarkan permasalahan tersebut 
maka perlu adanya skoring TB anak yang dapat membantu penegakan diagnosa TB pada anak dengan cepat dan tepat.

Sistem skoring TB anak merupakan salah satu pedoman untuk mendiagnosis TB pada anak sehingga dapat memberikan pengobatan dan perawatan anak dengan TB secara tepat. Sistem skoring TB anak dikembangkan dan direkomendasikan oleh ikatan dokter anak Indonesia, WHO dan Kemenkes RI untuk mempermudah menegakkan diagnosis TB pada anak ditatanan pelayanan kesehatan.

\section{Metode}

Penulisan artikel ini dimulai dari pencarian literature berbagai sumber pada electronic database melalui Google Schoolar, Proquest, ScieneDirect untuk mencari jurnal yang terkait dan terbit dari tahun 2013-2019. Metode penulisan yang dilakukan yaitu dengan Literature Riview dengan kriteria artikel yang diambil yaitu berkaitan dengan permasalah dan sistem skoring TB anak untuk mendiagnosis TB pada anak untuk memberikan pengobatan dan perawatan pada anak secara tepat dan berkesinambungan.

\section{Kajian Pustaka dan Pembahasan}

Tuberkulosis anak merupakan penyakit menular yang disebabkan oleh infeksi mycobacterium tuberculosis dan terjadi pada anak-anak. Faktor resiko penularan penyakit tuberkulosis pada anak sama seperti penularan pada umumnya yaitu tergantung pada tingkat penularan, lama pajanan dan daya tahan tubuh sesorang. Anak dengan hasil pemeriksaan BTA positif memiliki resiko besar untuk menularkan dibandingkan anak dengan hasil pemeriksaan BTA negative. ${ }^{(9)}$ Adapun cara penularan tuberkulosis itu sendiri melalui percik renik (droplet nuclel) yang berukuran sangat kecil yang mengandung bakteri mycobacterium tuberkulosis dan terhirup. Masa inkubasi TB yaitu sekitar 2-12 minggu. Selama masa inkubasi uji tuberkulin negatif pada seseorang sedangkan uji tuberkulin positif apabila imunitas selular tubuh terhadap TB terbentuk.

Tanda gejala klinis tuberkulosis pada anak yaitu demam, batuk, mengi, kelelahan dan kegagalan dalam penambahan berat badan anak. ${ }^{(10)}$ Gejala utama TB pada anak adalah batuk namun gejala tersebut jarang terjadi pada anak karena gejala TB pada anak tidak khas. Anak dengan gejala utama batuk dan/atau anak dapat mengeluarkan dahak, maka harus wajib diperiksa dahak dengan Tes Cepat Mokuler (TCM) atau mikroskopis SPS. Anak berumur kurang dari 3 tahun dengan manultrisi atau kondisi 
immunosupresan memiliki resiko paling tinggi menderita TB. Bayi dan balita memiliki resiko tinggi terkena TB berat seperti meningitis yang mampu menyebabkan buta, tuli dan kelumpuhan. ${ }^{(4)}$

Skrining TB, pencegahan dan pengobatan meruapakn bagian dari perawatan yang komprehensif dan perlu sitematis diterapkan untu anak-anak. ${ }^{(11)}$ Skrining TB merupakan bagian dalam penegakan diagnosa TB pada anak. Kesulitan dalam menentukan diagnosis TB pada anak dan kemajuan teknologi diagnostik yang hanya bisa dilakukan di pelayanan kesehatan yang lengkap membuat cakupan pengendalian TB masih rendah. Diagnosis TB pada anak tidak hanya berdasarkan foto torak saja, namun pemeriksaan bakteriologis (makroskopis atau TCM) merupakan pemeriksaan utama untuk menegakkan diagnosis TB pada anak. ${ }^{(4)}$ Adapun pendekatan untuk mengatasi masalah dalam menegakkan diagnosis TB pada anak dapat menggunakan sistem skoring TB anak.

Indonesia sudah mengembangkan sistem skoring TB anak yang disusun oleh Kementerian Kesehatan Rl Bersama IDAI. Sistem skoring TB anak merupakan pembobotan terhadap gejala, tanda klinis dan pada pemeriksaan penunjang serta dapat di aplikasikan pula pada layanan kesehatan yang memiliki sarana pelayanan kesehatan terbatas. ${ }^{(4,12)}$

Sistem skoring bermanfaat membantu menegakan diagnosa TB pada anak dan mengurangi kesalahan persepsi semua petugas kesehatan dalam menegakkan diagnosis TB dengan skoring yang sudah dibakukan. Parameter sistem skoring untuk TB anak meliputi kontak dengan orang sakit TB BTA positif diberi skor 3 bila ada bukti tertulis dari hasil laboratorium BTA, uji tuberkulin atau tes mantaoux, penentuan status gizi anak (berdasarkan berat dan tinggi badan yang diukur saat anak datang), demam, batuk kronik, pembesaran kelenjar limfe, pembengkaan tulang/sendi dan foto thorak.

Dalam sistem skoring anak didiagnosis TB bila skor $\geq 6$ dengan skor maksimal 13. Untuk daerah dengan fasilitas pelayanan kesehatan terbatas yaitu tidak tersedianya tes tuberkulin dan foto thorak bisa dapat digunakan sistem skoring ini dan anak dapat didiagnosis TB dengan syarat skor $\geq 6$. Anak dengan pembesaran kelenjar leher tidak selalu menderita TB anak, kemungkinan diagnosis lain seperti infeksi leher, amandel dan keganasan. Sedangkan kelenjar leher yang mendukung gejala TB pada anak bersifat tidak nyeri, multiple, diameter lebih dari $1 \mathrm{~cm} .{ }^{(4)}$ Anak yang sudah 
terskrining menderita TB anak harus segera mendapatkan pengobatan OAT 6-12 bulan tergantung dari ringan dan beratnya penyakit (Tabel 1).

Pada artikel tentang skoring TB anak dari Koura, et al pada Tahun 2015 yang melakukan uji coba skoring edwards modifikasi di rumah sakit Al Azher University dengan 60 anak-anak dengan pathozyme positif TB kompleks dan gejala pernafasan dan / atau dengan hasil X-ray. Adapun hasil dari penelitian bahwa skoring edwards modifikasi untuk mendignosis TB anak mempunyai hasil sensitifitas dan spesifitas untuk diagnosis paru lebih tinggi dengan skor 93.3\% dan 95\%. Penelitian ini menganjurkan untuk melakukan studi berbasis dengan ukuran sampel yang besar untuk mengevaluasi validitas skor. Adapun item yang dinilai didalamnya meliputi duration of illness, nutrition, family history of TB, tuberculin test, malnutrition, dan unexplained fever. ${ }^{(10)}$ Sistem skrong disajikan pada Tabel 2.

Tabel 1 : Sistem skoring TB anak di Indonesia

\begin{tabular}{|c|c|c|c|c|c|}
\hline Parameter & 0 & 1 & 2 & 3 & Skor \\
\hline Kontak TB & Tidak jelas & - & $\begin{array}{c}\text { Laporan } \\
\text { keluarga, BTA } \\
(-), \text { BTA tidak } \\
\text { jelas/tidak tahu }\end{array}$ & BTA $(+)$ & \\
\hline $\begin{array}{l}\text { Uji tuberkulin } \\
\text { (Mantoux) }\end{array}$ & Negatif & - & - & $\begin{array}{c}\text { Positif ( } \geq 10 \mathrm{~mm} \\
\text { atau } \geq 5 \mathrm{~mm} \text { pada } \\
\text { imunokompromais) }\end{array}$ & \\
\hline $\begin{array}{l}\text { Berat } \\
\text { badan/keadaan } \\
\text { gizi }\end{array}$ & - & $\begin{array}{c}\mathrm{BB} / \mathrm{TB}<90 \% \\
\text { atau } \\
\mathrm{BB} / \mathrm{U}<80 \%\end{array}$ & $\begin{array}{c}\text { Klinis gizi } \\
\text { buruk atau } \\
\text { BB/TB }<70 \% \\
\text { atau } \\
\text { BB/U<60\% }\end{array}$ & 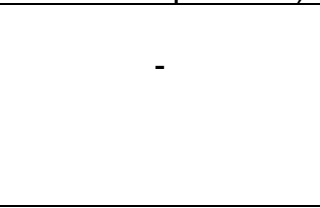 & \\
\hline $\begin{array}{l}\text { Deman yang } \\
\text { tidak diketahui } \\
\text { penyebabnya }\end{array}$ & - & $\geq 2$ minggu & - & - & \\
\hline Batuk kronik & - & $\geq 3$ minggu & - & - & \\
\hline $\begin{array}{l}\text { Pembesaran } \\
\text { kelenjar limfe } \\
\text { kolli, aksila, } \\
\text { inguinal }\end{array}$ & - & $\begin{array}{l}\geq 1 \mathrm{~cm} \text {, lebih } \\
\text { dari } 1 \mathrm{KGB}, \\
\text { tidak nyeri }\end{array}$ & - & - & \\
\hline $\begin{array}{l}\text { Pembengkakan } \\
\text { tulang/sendi } \\
\text { panggul, lutut, } \\
\text { falang }\end{array}$ & - & $\begin{array}{c}\text { Ada } \\
\text { pembengkaka } \\
n \\
\end{array}$ & - & - & \\
\hline Foto toraks & $\begin{array}{c}\text { Normal/kel } \\
\text { ainan tidak } \\
\text { jelas }\end{array}$ & $\begin{array}{c}\text { Gambaran } \\
\text { sugetif } \\
\text { (mendukung) } \\
\text { TB }\end{array}$ & - & & \\
\hline \multicolumn{6}{|c|}{ Skor Total (maksimal 13) } \\
\hline
\end{tabular}


Table 2: New modified Edward's score dengan Pathozyme TB Complex Test di Al Azher University

\begin{tabular}{lcccc}
\hline \multicolumn{1}{c}{ Score } & $\mathbf{0}$ & $\mathbf{1}$ & $\mathbf{2}$ & $\mathbf{3}$ \\
\hline Duration of illness/week & $<2$ & $2-4$ & & $>4$ \\
\hline Nutrition (\% weight for length) & $>80$ & $60-80$ & $<6$ \\
\hline Family history of TB & None & $\begin{array}{c}\text { Reported by } \\
\text { family }\end{array}$ & $\begin{array}{c}\text { Proved sputum } \\
\text { Positive }\end{array}$ \\
\hline Tuberculin test & & $\begin{array}{c}\text { Positive } \\
\text { Malnutrition }\end{array}$ & & after 4 weeks \\
\hline Unexplained fever (>2 weeks) & & $\begin{array}{l}\text { No response } \\
\text { to treatment }\end{array}$ & \\
\hline
\end{tabular}

Keterangan: jika skor 7 atau lebih, anak didiagnosis TB

Dari dua skoring TB pada anak di Indonesia dan luar negeri ada perbedaan dan persamaan. Adapun perbedaannya, di luar negeri terdapat item duration of illness, nutrition, family history of TB sedangkan item skoring Indonesia tidak ada. Sedangkan persamaan skoring Indonesia dan luar negeri yaitu item tes tuberculin, malnutrisi dan demam. Sistem skoring merupakan kebijakan pemerintah dari masing-masing negara dalam membuat SOP nya berdasarkan pertimbangan pertimbangan. Walaupun terdapat perbedaan item skoring di Indonesia dan luar negeri, tetap berfungsi dan bermanfaat dalam menegakan diagnosis TB pada anak.

Penelitian dilakukan oleh Naufal tahun 2010-2013 di puskesmas wilayah Tangerang Selatan terkait penggunaan skoring TB pada anak. Hasil penelitian menyatakan bahwa terdapat hubungan bermakna kejadian overdiagnosis TB anak dengan tidak tersedianya formulir skoring TB anak. Hal ini membuktikan bahwa adanya skoring TB anak dapat membantu tenaga kesehatan untuk mendiagnosis TB pada anak. ${ }^{(13)}$ Walaupun tidak semua fasilitas pelayanan kesehatan di Indonesia mempunyai pemeriksaan parameter yang ada pada skoring. ${ }^{(8)}$

Kemajuan tekhnologi semakin canggih, skoring TB anak untuk penegakan diagnosis dapat dibuat dalam bentuk aplikasi. Adapun aplikasi yang sudah ada yaitu aplikasi TB eSkoring berisi tentang item skoring TB anak dan rekomendasinya. ${ }^{(14)}$ Tidak terlepas dari penegakan diagnosa TB anak dan pengobatannya, maka diperlukan juga pemantauan selama pengobatan TB oleh petugas kesehatan.

\section{Kesimpulan}

TB anak merupakan penyakit yang disebabkan oleh bakteri mycobaterium tuberkulosa dan menjadi salah satu 
masalah kesehatan dunia termasuk di negara berkembang yaitu Indonesia. Penyakit tuberkulosis menjadi penyebab tingginya angka morbiditas dan mortalitas TB anak. Salah satu upaya mengatasi hal tersebut yaitu dilakukan pencegahan, penegakan diagnosa yang tepat, pengobatan dan pemantauan. Upaya penegakan diagnosa yaitu dengan menggunakan sistem skoring TB pada anak. Skoring TB pada anak selain untuk menegakkan diagnosa, juga mengurangi kesalahan persepsi antar petugas kesehatan dalam menegakkan diagnosis TB pada anak.

\section{Saran}

Sistem skoring TB yang baku pada anak mempermudah penegakan diagnosa anak dengan TB yang dilakukan oleh semua petugas kesehatan. Sehingga penting diadakan pelatihan untuk meningkatkan kemampuan petugas kesehatan terhadap skoring TB anak. Disamping itu seluruh tatanan pelayanan kesehatan diharapkan memiliki sarana yang lengkap untuk menilai parameter dalam sistem skoring TB anak supaya didapatkan data yang lebih akurat. Adanya kebijakan terkait keharusan penggunaaan skoring diseluruh tatanan pelayanan kesehatan juga diperlukan sehingga tidak terjadi overdiagnosis ataupun underdiagnosis.

\section{Daftar Pustaka}

1. Sangadji NW, Kusnanto $H$. Tuberculosis Paru Pada Anak Di Salatiga : Pengaruh Kondisi Rumah Dan Pendapatan Keluarga. 2018;121-6.

2. WHO. Child and Adolescent [Internet]. 2019. p. 2018-9. Available from: https://www.who. int/tb/areas-of-work/children/en/

3. Snow KJ, Sismanidis C, Denholm J, Sawyer SM, Graham SM. The incidence of tuberculosis among adolescents and young adults: a global estimate. 2017; Available from: http://dx.doi.org/10.1183/ 13993003.02352-2017

4. GERMAS. TB anak [Internet]. 2019. Available from: https://www. tbindonesia.or.id/dokumen/detail/4 2/tb-anak

5. Yustikarini $\mathrm{K}$, Sidhartani $M$, Yustikarini K, Sidhartani M. Faktor Risiko Sakit Tuberkulosis pada Anak yang Terinfeksi. 2015;17(16):136-40.

6. Kemenkes. Tuberkulosis: Temukan Obati Sampai Sembuh. 2015.

7. Carvalho I, Goletti D, Manga S, Silva DR, Manissero D, Migliori G. Managing Latent Tuberculosis Infection And Tuberculosis In 
Children. 2018;24(2):106-14.

8. Noviarisa Nurul, Finny Fitry BD. Tren Kasus Tuberkulosis Anak di RSUD Dr.Djamil Padang tahun 2014-2016. 2016;8(Supplement 1):36-41.

9. Kemenkes. Petunjuk Teknis Manajemen Dan Tatalaksana TB Anak. 2016.

10. Koura $H$, Mohammed AAF. Value of New Modification of Tuberculosis Score in Diagnosis of Childhood Pulmonary Tuberculosis. 2015;5(3):39-44.

11. Detjen AK, Essajee S, Grzemska M, Marais BJ. Tuberculosis and integrated child health Rediscovering the principles of Alma Ata. Int $J$ Infect Dis. 2019;80:S9-12.

12. Bakthiar. Jurnal Kedokteran: pendekatan Dignosis Tuberkulosis Pada Anak Di Sarana Pelayanan Kesehatan Dengan Fasilitas Terbatas.Banda Aceh. 2016.

13. Farisatrianto N. Prevalensi Overdiagnosis Tb Anak Berdasarkan Sistem Skor Tb Anak Di Puskesmas Wilayah Kota Tangerang Selatan. 2013;
14. Udayanti ED, Nugroho FA. Analisa Minat Penggunaan Aplikasi TB eSkoring dengan Pendekatan Technology Acceptance Model (TAM). Edu Komputika J. 2018;5(1):1-12. 